\title{
Optimization for Fermentation of Cattle Manure to Produce Bio-Fertilizer by Inoculating Complex Microbial Agents
}

\author{
Ruimin $\mathrm{Fu}^{1,2}$ Fang $\mathrm{Lin}^{3}$, Hong Zhang ${ }^{1}$, Wenhui Xing ${ }^{1}$, Huiping Chang ${ }^{1}$ and Wuling Chen ${ }^{*}, 2$ \\ ${ }^{I}$ Department of Life Science, Henan Normal of Education, Zhengzhou 450046, China \\ ${ }^{2}$ College of Life Science, Northwest University, Xi'an 710069, China \\ ${ }^{3}$ Department of Life Science and Technology, Xinxiang University, Xinxiang, 453003, China
}

\begin{abstract}
In this study, in order to determine the optimization technology of bio-fertilizer, the aerobic fermentation test was conducted by using fresh manure and rice husk powder as materials. The inoculation, moisture content, $\mathrm{C} / \mathrm{N}$ ratio and turning frequency analysed by single-factor test. Following this, the optimal conditions in the first fermentation were obtained through orthogonal experiments. After the first fermentation, the second fermentation was carried out by adding complex microbes with the ability to release potassium, dissolve phosphate and fix nitrogen. The termination time of second fermentation was determined by testing the growth condition of beneficial bacteria in the fermentation process. The results show, that the optimal parameter in the first fermentation contained moisture content of $70 \%, \mathrm{C} / \mathrm{N}$ ratio of $20: 1$, inoculation of $3 \%$, and turning frequency of once every three days. After a period of fifteen days of fermentation, the germination index reached $91.3 \%$. Following this, second fermentation was conducted at the sixth day and the germination index was increased to $98.8 \%$. Under this optimum condition, the material could heat up fast and the top temperature could be high with a long duration.
\end{abstract}

Keywords: Bio-organic fertilizer, cattle manure, complex microbial agents, fermentation.

\section{INTRODUCTION}

With the establishment of the large amount of intensive pasture, more manure has been produced [1,2]. The manure has become a major source of ecological environmental pollution [3], which is not only harmful for the environment and human health, but also influences the sustainable development of livestock industry. Moreover, manure contains a large amount of organic matter and other nutrients composition such as $\mathrm{N}, \mathrm{P}, \mathrm{S}, \mathrm{K}$, etc. After processing, it can become a good agricultural fertilizer [4-6]. Aerobic fermentation is the most effective way of treating manure harmlessly and resourcefully $[7,8]$. In the fermentation process, a large number of nitrogen, phosphorus and potassium compounds useful for plant growth are produced by microbial degradation. Moreover, the synthesis of new organic polymer - humus could be an important active substance for soil fertility [9]. However, due to limited indigenous microorganisms and fermentation technology, the traditional fermentation process has not been widely used before. Currently, some reports have indicated that the fermentation efficiency could be improved by inoculating microbial agents [10-14]. However, there is little research on the optimization of process parameters. In this study, the main parameter of first fermentation was optimized by single factor test and orthogonal experiments. In the second fermentation, the additional phosphate-dissolving bacteria released soluble phosphorus to plants by dissolving

*Address correspondence to this author at the College of life Science, Northwest University, Xi'an, China; Tel: +86-15137196345; E-mails: wulingchen@yeah.net; angelaminmin@163.com insoluble tricalcium phosphate. The silicate bacteria degraded silicate minerals and released the potassium for plant growth. Meanwhile, the nitrogen fixation bacteria fixed the nitrogen and supplied it to the plant. Therefore, these beneficial microbes can be added in the soil to provide crop nutrients or produce hormones to stimulate plants.

In this study, aiming at producing biological organic fertilizer, secondary fermentation process was conducted and different composite microbial agents were added at different stages of fermentation. The main process parameter was optimized and the optimal fermentation conditions were explored to improve the fermentation efficiency.

\section{MATERIAL AND METHODS}

\subsection{Fermentation Materials}

Fresh cattle manure and rice husk powder were used as fermentation materials. The main physical and chemical properties are shown in Table $\mathbf{1}$.

\subsection{Preparation of Complex Microbial Agents in the First Fermentation}

Trichoderma viride, Aspergillus oryzae, Bacillus subtilis and Pseudomonas sp., which were isolated and saved in the laboratory, were respectively increased for expanding culture step by step to prepare the solid microbial agents. Following this,Trichoderma viride, Aspergillus oryzae, Bacillus subtilis and Pseudomonas sp., were mixed in the proportion of 2:1:1:2 to produce mixed microbial agents. 
Table 1. Main physical and chemical characteristics of compost material.

\begin{tabular}{|c|c|c|c|c|c|c|}
\hline Material & Moisture Content (\%) & pH Value & Organic Matter (\%) & C / N Ratio & Total Carbon (\%) & Total Nitrogen (\%) \\
\hline \hline cattle manure & 90 & 8.0 & 66.2 & 20.6 & 39.8 & 1.93 \\
\hline rice husk powder & 10 & 7.0 & 71.6 & 70.6 & 45.6 & 6.46 \\
\hline
\end{tabular}

2.4. Preparation of Complex Microbial Agents in the Second Fermentation

Azotobacter choococcum which could fix nitrogen, Bacillus megaterium which could dissolve phosphorus and Bacillus mucilaginosus which could dissolve potassium, were respectively cultured in liquid under the condition of $180 \mathrm{rpm}, 30^{\circ} \mathrm{C}$. When the cell concentration reached $10^{9} \mathrm{CFU} / \mathrm{mL}$, they were respectively mixed with sterilized bran in the proportion of $1: 1$ to prepare solid agents. The solid agents of Azotobacter choococcum, Bacillus megaterium and Bacillus mucilaginosus were mixed together with the same ratio to produce mixed microbial agents.

\subsection{The First Fermentation Design}

Static composting experiment was carried out by piling up the material to 2 meters long, 1 meters wide, and 0.8 meters high. Inoculation, moisture content, $\mathrm{C} / \mathrm{N}$ ratio and turning frequency were analyzed by single factor test. In this study, temperature and germination indexes were considered as evaluation index to identify the optimal range of four factors. After testing four factors by orthogonal test, the optimum fermentation parameters were determined With the ambient temperature being about $30^{\circ} \mathrm{C}$.

\subsection{The Second Fermentation Design}

When the first fermentation temperature dropped to 45 ${ }^{\circ} \mathrm{C}$, adding Azotobacter choococcum, Bacillus megaterium and Bacillus mucilaginosus released potassium, dissolved phosphate and fixed nitrogen to conduct a second fermentation,with the turning frequency being once a day and keeping the temperature suitable for bacterial growth and reproduction. Viable count of bacteria was tested to determine the terminal time of the secondary fermentation process.

\subsection{Determination of the Indicators}

The temperature was detected by a glass thermometer. The moisture content and $\mathrm{C} / \mathrm{N}$ ratio were tested according to the organic research method [15] and potassium dichromate sulfuric acid digestion method [16]. The seed germination index was tested as follows: 30 rape seeds were put into a petri dish lined with filter paper. After adding $5 \mathrm{~mL}$ of fermentation product extracts into the petri dish and taking distilled water as control, all the petri dishes were kept into the seed germination boxes at $25^{\circ} \mathrm{C}$ for $96 \mathrm{~h}$. Following this, the germination rate and the root length were measured and calculated according to the following formula:

Germination index $\%=($ seed germination rate in test group $\times$ the length of seed root in the test group)/(seed germination rate in control group $\times$ the length of seed root in the control group) $\times 100 \%$.

\section{RESULTS}

\subsection{Influence of Moisture Content on Cattle Manure Fermentation}

The effect of moisture content on germination index and on fermentation temperature is respectively shown in Table 2 and Fig. (1). When the moisture content reached $60 \%$, the material warming increased with the maximum temperature (Fig. 1) of $68{ }^{\circ} \mathrm{C}$ and the high temperature could hold 8.5d. All the treatment was in line with the Chinese Ministry of Agriculture industry standards (NY / T 394-2000) hygiene standards. When the moisture continued to increase, the temperature gradually declined, due to excessive moisture limiting the aerobic microorganisms' contact with oxygen. Meanwhile, the germination index (Table 2) was maintained above $80 \%$ when the moisture content was between $60 \%$ $80 \%$.

\subsection{Influence of $\mathrm{C} / \mathrm{N}$ Ratio on Cattle Manure Fermentation}

The effect of $\mathrm{C} / \mathrm{N}$ ratio on germination index and on fermentation temperature is respectively shown in Table $\mathbf{3}$ and Fig. (2). When the $\mathrm{C} / \mathrm{N}$ ratio reached 30:1, the material warming increased with the maximum temperature (Fig. 2) of $65^{\circ} \mathrm{C}$ and the high temperature could hold $8.5 \mathrm{~d}$. All the treatment was in line with the Chinese Ministry of Agriculture industry standards (NY/T 394-2000) hygiene standards. Meanwhile, the germination index (Table 3) was maintained above $86.6 \%$ when the $\mathrm{C} / \mathrm{N}$ ratio was $30: 1$.

\subsection{Influence of Turning Times on Cattle Manure Fermentation}

The effect of turning frequency on germination index and on fermentation temperature is respectively shown in Table 4 and Fig. (3). Due to different turning frequencies, the temperature trends in the fermentation were basically the same, which experienced heating period, high temperature period and cooling period. When the turning frequency was once every 3 days, the material warming increased with the maximum temperature (Fig. 3) being $65^{\circ} \mathrm{C}$. This manifested because the turning frequency increased the ventilation rate in the fermentation. However, extensive turning could cause the heat loss. The germination index (Table 4) could be maintained above $80 \%$ when the turning frequency was once every 3 days or once a day. 


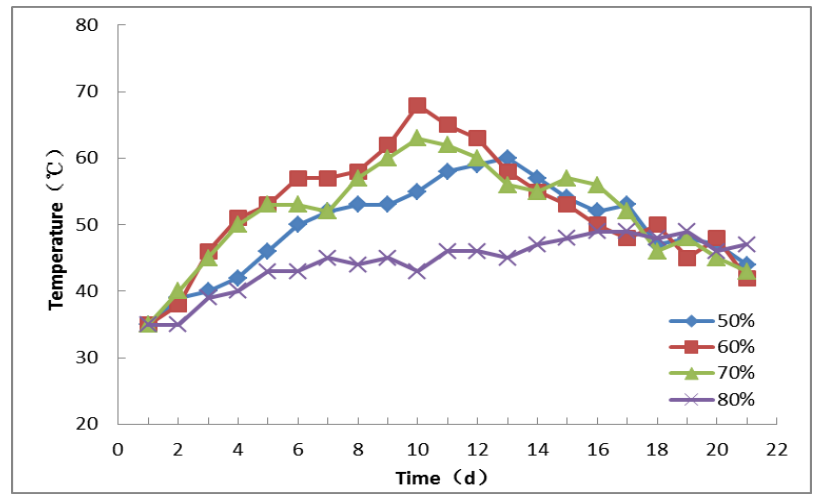

Fig. (1). Effect of moisture content on fermentation temperature.

Table 2. Effect of moisture content on germination index.

\begin{tabular}{|c|c|c|c|c|}
\hline Moisture content (\%) & 50 & 60 & 70 & 80 \\
\hline Germination index (\%) & 80.8 & 88.6 & 86.6 & $<50$ \\
\hline
\end{tabular}

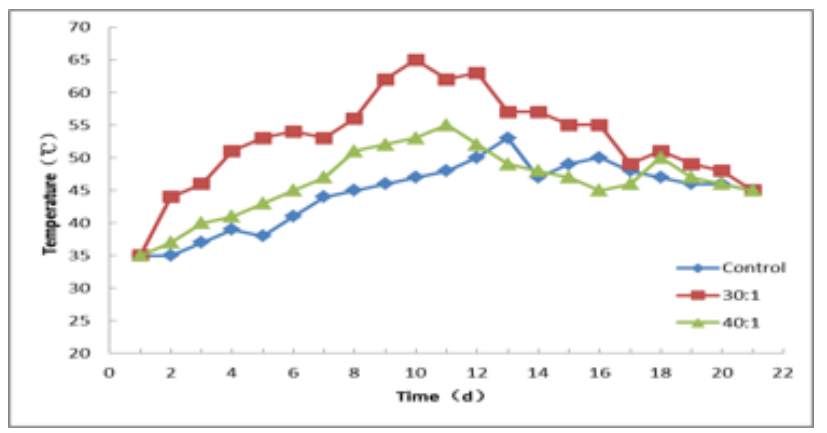

Fig. (2). Effect of $\mathrm{C} / \mathrm{N}$ ratio on fermentation temperature.

Table 3. Effect of $\mathrm{C} / \mathrm{N}$ ratio on germination index.

\begin{tabular}{|c|c|c|c|}
\hline $\mathbf{C} / \mathbf{N}$ & Control (20:1) & $30: 1$ & $40: 1$ \\
\hline Germination index (\%) & 70 & 86.6 & 72 \\
\hline
\end{tabular}

\subsection{Influence of Inoculation on Cattle Manure Fermentation}

The effect of inoculation on germination index and on fermentation temperature is respectively shown in Table $\mathbf{5}$ and Fig. (4). From Fig. (4), it was observed that the temperature increased rapidly with an increase in the rate of inoculation. Meanwhile, the germination index (Table 5) could be maintained above $80 \%$ when the inoculation amount was between $2 \% 0-3 \%$.

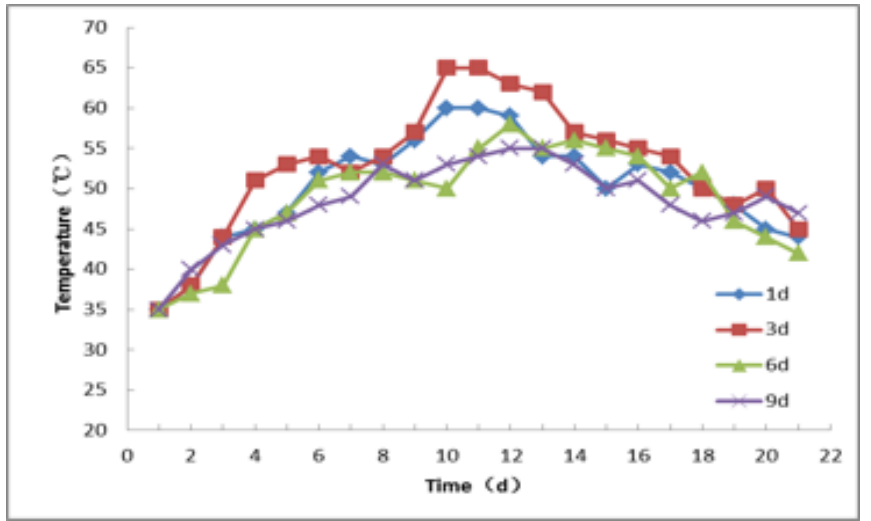

Fig. (3). Effect of turning frequency on fermentation temperature.

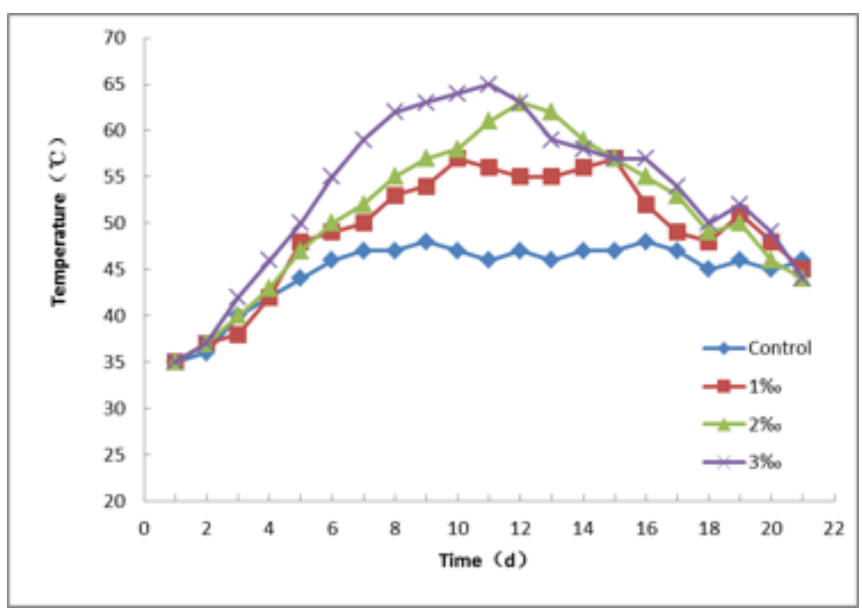

Fig. (4). Effect of inoculation on fermentation temperature.

\subsection{The Determination of Optimum Conditions in the Fermentation}

In order to optimize the fermentation process, four factors were analyzed and three levels orthogonal experiment were conducted according to the optimal range of factors resulting from single-factor test. The result is shown in Table 6. By analyzing the range, the relationship between the primary and secondary factors was observed to be $\mathrm{D}>\mathrm{B}>\mathrm{A}$ $>\mathrm{C}$, which suggests that the complex microbial inoculants were the main source of influence on the fermentation. The optimum fermentation conditions were combined into $\mathrm{A}_{2} \mathrm{~B}_{1} \mathrm{C}_{2} \mathrm{D}_{3}$, which inculded moisture content of $70 \%, \mathrm{C} / \mathrm{N}$ ratio of 20:1, turning frequency of once every three days, and inoculation of $3 \%$. Under this condition, the germination index could reach $91.3 \%$.

Table 4. Effect of turning frequency on germination index.

\begin{tabular}{|c|c|c|c|c|}
\hline Turning Frequency & Once a Day & Once Every Three Days & Once Every Six Days & Once Every Nine Days \\
\hline Germination index (\%) & 70 & 86.6 & 72 & 68 \\
\hline
\end{tabular}

Table 5. Effect of inoculation on germination index.

\begin{tabular}{|c|c|c|c|c|}
\hline Inoculation & Control (without Microbe Addition) & $1 \% 0$ & $2 \%$ & $3 \%$ \\
\hline Germination index (\%) & $<50$ & 71.6 & 89.6 & 91.8 \\
\hline
\end{tabular}


Table 6. Results of orthogonal experiment.

\begin{tabular}{|c|c|c|c|c|c|}
\hline No. & $\begin{array}{c}\text { A Moisture Content } \\
\%\end{array}$ & B C/N Ratio & $\begin{array}{l}\text { C Turning } \\
\text { Frequency }\end{array}$ & D Inoculation & $\begin{array}{c}\text { Germination Index } \\
(\%)\end{array}$ \\
\hline 1 & 60 & 20 & 2 & 1 & 82.3 \\
\hline 2 & 60 & 30 & 3 & 2 & 84.2 \\
\hline 3 & 60 & 40 & 4 & 3 & 86.6 \\
\hline 4 & 70 & 20 & 3 & 3 & 91.3 \\
\hline 5 & 70 & 30 & 4 & 1 & 88.5 \\
\hline 6 & 70 & 40 & 2 & 2 & 81.3 \\
\hline 7 & 80 & 20 & 4 & 2 & 82.2 \\
\hline 8 & 80 & 30 & 2 & 3 & 89.2 \\
\hline 9 & 80 & 40 & 3 & 1 & 83.6 \\
\hline K1 & 84.367 & 85.267 & 84.267 & 84.800 & -- \\
\hline K2 & 87.033 & 87.300 & 86.367 & 82.567 & -- \\
\hline $\mathrm{K} 3$ & 85.000 & 83.833 & 85.767 & 89.03 & -- \\
\hline $\mathrm{R}$ & 2.666 & 3.467 & 2.100 & 6.466 & -- \\
\hline
\end{tabular}

\section{CONCLUSION}

In this study, single factor test and orthogonal test were used to optimize bio-organic fertilizer fermentation. The optimum parameters involved; moisture content of $70 \%, \mathrm{C} / \mathrm{N}$ ratio of 20:1, turning frequency of once every three days, and inoculation of $3 \%$. Under this condition, the germination index could reach $91.3 \%$ after the first fermentation. Subsequently, the second fermentation was conducted by adding complex microbial agents to improve soil fertility. After the second fermentation, the germination index was increased to $98.8 \%$. Under the optimal conditions, the cattle manure heated up fast and the maximum temperature was achieved with a long duration. Moreover, fermentation cycles did not reduce with high maturity. This study provides necessary parameters and theoretical basis for the production of bio-organic fertilizer.

\section{CONFLICT OF INTEREST}

The authors confirm that this article content has no conflict of interest.

\section{ACKNOWLEDGEMENTS}

This work was financially supported by Agricultural Science and Technology Achievements Transformation Fund Project (2012GB2G000451) and Youth Scientific Research Projects in Henan Institute of Education (20100103).

\section{REFERENCES}

[1] Montes F, Meinen R, Dell C, et al. SPECIAL TOPICS - mitigation of methane and nitrous oxide emissions from animal operations: II. A review of manure management mitigation options. J Anim Sci 2013; 91(11): 5070-94.

[2] Guo D-J, Wu H-S, Ma Y, Chang Z-Z. Study on the Amount of Manure and Urine Excreted by Sheep and Rabbits in Intensive Pasture. J Ecol Rural Environ 2011; 1: 010.

[3] Heuer H, Schmitt H, Smalla K. Antibiotic resistance gene spread due to manure application on agricultural fields. Curr Opin Microbiol 2011; 14(3): 236-43.

[4] Bouwman L, Goldewijk KK, Van Der Hoek KW, et al. Exploring global changes in nitrogen and phosphorus cycles in agriculture induced by livestock production over the 1900-2050 period. Proc Natl Acad Sci USA 2013; 110(52): 20882-7.

[5] Holden S, Lunduka R. Do fertilizer subsidies crowd out organic manures? The case of Malawi. Agric Econ 2012; 43(3): 303-14.

[6] Chakraborty A, Chakrabarti K, Chakraborty A, Ghosh S. Effect of long-term fertilizers and manure application on microbial biomass and microbial activity of a tropical agricultural soil. Biol Fertil Soils 2011; 47(2): 227-33

[7] Müller C, Johansson M, Salomonsson AC, Albihn A. Effect of anaerobic digestion residue $v s$ livestock manure and inorganic fertilizer on the hygienic quality of silage and haylage in bales. Grass Forage Sci 2014; 69(1): 74-89.

[8] Elsaidy N, Abouelenien F, Kirrella GA. Impact of using raw or fermented manure as fish feed on microbial quality of water and fish. Egypt J Aquatic Res 2015; 41(1): 93-100.

[9] Erhart E, Siegl T, Bonell M, et al. Fertilization with liquid digestate in organic farming-effects on humus balance, soil potassium contents and soil physical properties. EGU General Assembly Conference Abstracts 2014.

[10] López I, López R, Santamaría P, Torres C, Ruiz-Larrea F. Performance of malolactic fermentation by inoculation of selected Lactobacillus plantarum and Oenococcus oeni strains isolated from Rioja red wines. Vitis 2015; 47(2): 123.

[11] Jiang J, Liu X, Huang Y, Huang H. Inoculation with nitrogen turnover bacterial agent appropriately increasing nitrogen and promoting maturity in pig manure composting. Waste Manag 2015; 39: $78-85$. 
[12] Liu L, Li T, Wei X, Jiang B, Fang P. Effects of a nutrient additive on the density of functional bacteria and the microbial community structure of bioorganic fertilizer. Bioresource Technol 2014; 172: 328-34.

[13] Xiong S, Xu W, Yang Y, et al. Effects of microbes and cellulase in pig manure fermentation at different temperature. Acta Scientiae Circumstantiae 2014; 12: 028 .

[14] Li J, Yu J, Feng Z, et al. Effect of different microbial inoculants on aerobic composting of cow manure. J Arid Land Resour Environ 2014; 2: 019.
[15] Braude EA, Nachod FC. Determination of organic structures by physical methods: Elsevier 2013.

[16] Edenborn S, Edenborn H, Krynock R, Haug KZ. Influence of biochar application methods on the phytostabilization of a hydrophobic soil contaminated with lead and acid tar. J Environ Manag 2015; 150: 226-34.

(C) Fu et al.; Licensee Bentham Open.

This is an open access article licensed under the terms of the Creative Commons Attribution Non-Commercial License (http://creativecommons.org/licenses/ by-nc/4.0/) which permits unrestricted, non-commercial use, distribution and reproduction in any medium, provided the work is properly cited. 